\title{
Development of Financial Supply Chain Management and Supply Chain Finance Model
}

\author{
Mehdi Fathollah* \\ Faculty Member of Islamic Azad University, Karaj Branch, Alborz, Iran \\ Hamidreza zargar \\ Islamic Azad University, Karaj Branch, Alborz, Iran
}

\begin{abstract}
Expansive economic, production and commercial development today has made businesses and enterprises to have active presence and contribution in network-based and chain economy. Although focusing on this approach has brought some privileges and productivities for the firms which are members of networks and supply chains, it has been accompanied by various problems and complexities for financial crisis management, cash flow and flow capital amount of the foundations and their commercial partners. To overcome such problem, besides developing the concepts of supply chain management and logistics, Financial Supply Chain Management (FSCM) was also promoted to minimize inefficiencies of financial flow in supply chain using financial, engineering and management approaches, and to provide an effective management ground for cash inventory and flow capital all throughout the supply chain by making use of various tools and techniques of supply chain finance and/or SCF. Hence, by changing approach and role of financial services provider from just supplier of financial resources as the commercial partners of economic and commercial firms, it caused that a major part of managerial duties of financial flow of chain enterprises could be defined in collaboration with financial services provider, and they may be executed in a more desirable manner considering the capacities and capabilities of banks and financial institutes. Thus, regarding the significance of financial flow management in the chain and benefitting the principles and fundamentals of research by fact finding and case study, it was tried to present a framework to make use of financial flow management and its principles and fundamentals effectively by reviewing evidences as well as applicable experiences in this area. The present paper emphasized that as logistic services providers are responsible in supply chains to improve inventory level; financial services providers also have the same role concerning liquidity level in the chains. Therefore, by making coordination and integrity in the inventory flows, information and financial flows through supply chain, we can handle financial risks and provide more stable value flow in supply chain till distribution, and create a ground better for materializing objectives of the firms which are members of supply chain.
\end{abstract}

Keywords: Financial Supply Chain Management, Supply Chain Finance, Supply Chain Management, Financial Services Providers.

DOI: $10.7176 /$ RJFA/10-1-03

\section{Introduction}

Small businesses and weak interactions among institutions seem to be a great obstacle to develop synergy in economy, production and commerce. While all these issues are the essence of manufacturing and commercial units. Obtaining conductive and supportive policies to develop and organize supply chain of various businesses and also to make network for businesses facilitated integration of institutions to remove the aforesaid problems partially. In the current condition of world economy, active institutions seek network businesses and intend to strengthen supply chain in order to distribute their business to create and promote the competitive privileges. Development of supply chains and making capable business can be so significant that could just be defined within the framework of this integration. Hence, supporting networks and chains can be parallel to economic efficiency, decrease transaction expenses, create synergy and materialize other crucial benefits. In any business, financial resources and capital are considered as the most significant elements of production, and entrepreneurs and investors shall provide necessary fund or financial finance to produce their product and/or to present their services. While the alternation in the approach and manufacturing and commercial models from individual and independent businesses to chain-based and network enterprises have developed new requirements and expectations for manufacturing institutions and members of chains and business networks in order to commence and continue their operation to gain stable value and to preserve the desired business [1]. Financial resources and the required fund for the institutions can be provided through various ways. The ability of institutions to supply financial resources and to provide appropriate financial plans is considered as the major elements to grow and develop a business. It goes without saying that if such ability is formed within the framework of communications and interactions among various enterprises along with one chain, it can provide stable competitive privileges for that business chain which will benefit more value. Institution may take different actions to supply their required financial resources. Financial resources of an institution can be provided through its owners and shareholders 
(internal resources - undivided profit) and/or through external resources other than shareholders' fund, or by money and capital markets. Hence, obtaining proper policies for effective management of financial flow in the supply chain is an issue which shall be considered specifically. Liquidity cycle management, receivable/payable accounts and inventory optimized management, administration of financial resources supply, risk management, legal and insurance affairs management and other required specialized services are some of the requirements of success in chain-based businesses which should be regarded along with a chain supply besides management of goods and information flow [14]. As mentioned before, the efficiency of supply chain management is the result of coordination of various courses of goods, information and finally financial flow. During last three decades, great endeavors have been taken to improve and promote supply chain efficiency (such as significant decrease in delay time, less inventory, more responsiveness, enhancement of products variety, more collaboration in planning and forecasting and better presentation of services to customers); however, administration of financial circulation of supply chain is executed as performed in 1970s. Remarkable delays in processing and registration of bills and invoices, days sales outstanding (DSO) and great amount of liquidity to supply working capital besides the existing uncertainty are some of the specifications of financial management in a number of current supply chains. Current economic conditions have made fragile and great number of risks in commerce and business. These risks which are mostly financial ones have been demonstrated more particularly after economic and financial crises during the previous years. Unpredictable world economy in the present circumstances and harder provision of financial resources have caused commercial flows and expanded financial pressures have influence not only on world purchasers but also on ever-increasing number of suppliers. This event increases risk of companies which shall be handled properly. Therefore, increase in production expenses, problems of financial resources and cash management, complexities dominant on financial supply methods and management problems of receivable and payable accounts in the chain and many other similar issues have attracted attentions to a subject called "Financial Supply Chain Management" [5]. To optimize these financial processes, Financial Supply Chain Management helps companies to consider all the chain beyond their own institution realm. This holistic approach focused on collaboration with other members inside the chain and it is publicized as an appropriate method for financial flow management in line with protection of strategic factors of supply chain. Thus, new consideration are emerged in making coordination among financial management and logistic management and supply chain which has created new business fields, particularly for banks and the organizations presented financial services $[15,16]$. Optimization of cash flow through operating processes of supply chains not only brings about satisfaction of chain beneficiaries, but increases efficiency of chain supply and leads to a win-win attitude both for financial supply foundations and the companies which are member of supply chain [3]. Nonetheless, a limited number of financial suppliers and banks discussed this issue. While the concept of financial supply chain management is unknown for many companies and banks and its benefits are unclear and presented solutions are also complicated.

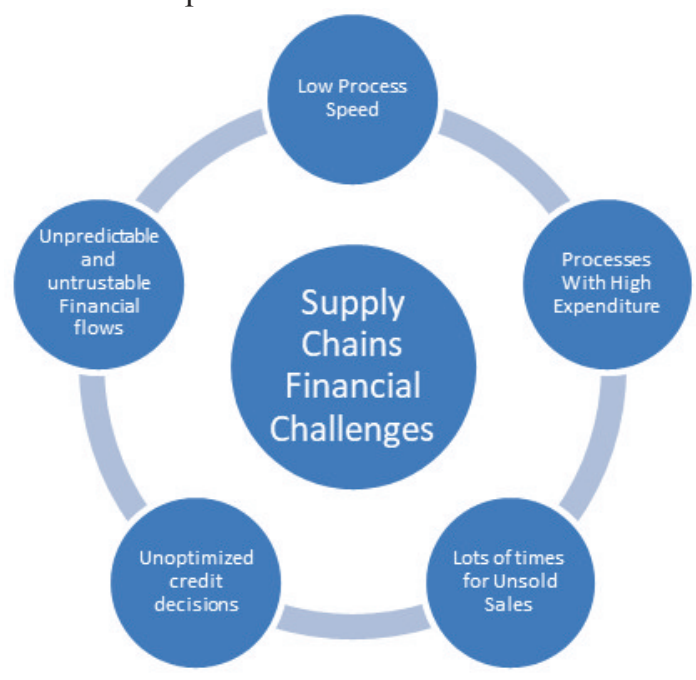

Figure 1. Financial Supply Chains Challenges

It should be mentioned that although various financial factors are presented in SCOR (Supply Chain Operations Reference) and Du Pont Model and assisted managers in creating a link between financial status and operating performance, it is able to inform the relevant authorities to adopt decisions concerning influence of their actions on financial flows, the aforesaid issues are deprived of any flexibility to cover the subjects related to management of financial flow through a chain $[7,8]$. 


\subsection{Review of Literature, Definitions \& Concepts}

\section{A. Financial Supply Chain Management}

"Financial Supply Chain Management" may mean differently from various viewpoints in supply chain including: logistic services provider (LSP), information services providers (ISP) and financial services providers (FSP). This concept commences from a simple definition "cash flow management (including financial payment or short-term financial supply) among members of a supply chain", and in some other definitions, it emphasizes on management of investment expenses or financial supply for whole supply chain and method of such expenses. FSCM contains a number of approaches and services to accelerate financial and information resources flow among commercial partners in supply chains [3]. Based on another definition, FSCM concept includes facilitating financial supply tools for supply chains by banks and institutes of third party financial services providers through introducing processes and modern payment conditions by these financial institutes for the partners of supply chain. Another viewpoint to "Financial Supply Chain Management" shall be expressed after calculating all the expenses of financial activities [19] which occur in a supply chain and among its members and also determining method of decreasing those expenses without imposing risk on weaker members of supply chain. Another approach to "Financial Supply Chain Management" defines it as a series of processes which include cash exchange, inventories and information management in supply chain. In this concept, FSCM is a series of cross-functional processes which manage key processes related to risk, working capital and information management. Based on another definition, financial supply chain management is detecting methods of effective management and optimizing working capital of a company; not only from internal viewpoint of organization but from an external view of organization (i.e. from standpoint of other members of a chain). This optimization can be implemented through collaboration in payable accounts, receivable accounts, liquidity and risk. The final goal of financial supply chain management is to obtain clarity and demonstration of purchase processes up to payment and ordering till receiving cash [11]. This cash-to-cash cycle is one of the most important factors effective in success of supply chain. This may lead to efficiency and profitability besides saving expenses in one supply chain. Better optimization of financial processes and flows by companies, less working capital will be required, thus less financial credits will be demanded from banks. This approach will result in saving in expenses and therefore in creating more investment opportunities for all members of supply chain. Companies usually focused on financial supply chain management when the following issues seem to be so significant [56].

> Creating stable value flow and increasing efficiency and profitability of supply chain;

$>$ Clarifying and increasing efficiency of the processes subject to financial supply chain management;

$>$ Decreasing expenses of supply chain;

$>$ Administrating deficiency and/or extra funds and cash and supplying working capital through chain;

> Having effective collaboration with partners of financial supply chain and improving relation and interaction among members of supply chain;

$>$ Integrating and coordination of systems, methods, procedures and structures of financial flow through chain;

> Applying the methods and techniques suitable for financial supply through chain;

$>$ Required to make use of proper technology to guarantee information exchange and financial documents from buyer to bank and from bank to supplier through chain;

$>$ Necessity for measuring and assessing financial flow in supply chain.

B. Supply Chain Finance (SCF)

As it was mentioned before, working capital is one of the major indicators in expressing supply chain efficiency, and the existing organizations in chain intend to optimize it. This indicator is usually calculated as follows:

Working Capital ${ }^{1}=$ current assets - current debts

Where current assets include inventories, receivable accounts, banking accounts, cash and negotiable papers, and current debts include payable accounts, current liabilities etc. Hence, institutions have tried to obtain optimized amount of working capital to develop their business by equalizing the said components. It should be mentioned that attention to moderating working capital is the relation of this subject with two factors of profitability and credit risk of business. On the other side, it was intended in financial supply chain management theory to manage working capital of one by one institutions which are members of the chain besides emphasizing on management of working capital of all the chain totally in order to optimize the entire working capital [15].

Unfortunately, in not too distant past, traditional approaches used for improvement of working capital and cash-to-cash cycle were concentration on one organization and no significant attention was paid to other existing organization in supply chain. Applying this approach has led to local optimization of working capital in some parts of supply chain, and transferring working capital to some other parts of the chain caused problems in them,

\footnotetext{
${ }^{1}$ Working capital simply means the liquidity required for a business for its daily works. In more precise definition: It is the difference of short-term capitals and short-term liabilities (debts).
} 
and it may result in stopping business of other elements of the chain. To prohibit emergence of such types of problems of business, moderating goal and optimization of working capital of the chain shall have priority over optimization of its own working capital, and to increase profitability for the entire chain and decrease risk for the entire chain. Development of this perception resulted in formation of supply chain finance (SCF) concept which seeks opportunities through which the working capital of all involved components could be improved. Hence, it can stated that SCF is a set of financial techniques, approaches and tools which are used for optimization of transactions, working capital and expenses throughout the supply chain, from designing products to handling after sale services and all the planning procedures, supply, procurement, production, warehouse management and distribution. Of course, some other definitions are presented for SCF. For instance, some resources deem SCF as the demonstration of available financial tools to supply capital for goods and products all throughout the supply chain and they are aware of every movement from origin to the destination. Some other also recognize SCF combination of commerce financial supply which is provided by a financial institute or a third party seller and/or the organization itself, and consider it as a technological ground leading to unity and integration of electronic exchanges of parties in a transaction and commence finance based on one or more event(s) in supply chain. Common points in the said definitions and other presented definitions for SCF demonstrated that the final goal of SCF is optimization of working capital of all supply chain $[16,17]$. Thus, the organization using such tools will probably have a less expensive and more stable experience (financially) in supply chain which this may lead to a strategic privilege for the desired chain and organization. It can be declared that SCF provides conditions and opportunities for collaboration of supply chain elements in which all the parties in the transaction shall be benefitted and the working capital of the entire chain is improved. As mentioned before, supply chain finance seeks development of techniques and tools to be facilitated in supply chain exchange. Some of the solutions in line with gaining this aim used by advanced financial services providers include:

$>$ Pre-Shipment Finance

$>$ Post-Shipment Finance

$>$ Buyer Finance

$>$ Export Credit Agencies, ECA, Supplier Financing

$>$ Warehouse Finance

$>$ Distribution Finance

$>$ Bank Assisted Open Account

$>$ Open Account Payment

To conclude the presented concepts, it can be stated that FSCM can manage and optimize cash flow and working capital all throughout the supply chain to manage and optimize cash flow and financial supply through enterprise value chain. Considering dynamic essence of financial issues of supply chain, Chief Financial Officers (CFO) of organization requires using various tools, techniques and solutions to gain the objectives related to working capital of organization. Such tools and techniques are in fact different methods of Supply Chain Finance (SCF), and they shall be so fundamental and essential that provide positive influence on financial flow of business supply chain. Decreasing expenses of finance and optimizing cash flow in supply chains can be considered as the main operations of SCF. SCF are set in a way that to be a stimulant for development of supply chain, risk adjustment and creating value through improving operation performance related to financial resources establishment [13].

\section{Research Methodology}

The research methodology in this study is fact finding. By fact finding, we mean designing a scientific and systematic structure to describe and interpret a phenomenon based on recognized evidences and experiences. In other words, fact finding means discovering and obtaining reality and trueness of any phenomena based on experiences, then it discusses quality and explains reason of the desired phenomena relations [20]. Hence, it was endeavored to explain literature of the issue and also to review experience of a number of accredited banks concerning applying financial supply chain management system as well as supply chain finance by recognizing applicable experiences of this subject. Pursuant to performed investigations, a conceptual framework was presented to explain function of financial sully chain management system. It should be mentioned that to review authenticity and validity of the results of this research, the framework of proposed system was evaluated in specialized panels by specialists and elites of state banking industry and they were validated.

\section{Review of Experiences of Financial Services Providers}

The range of presenting services for the majority of world banks now id limited to strategic dimensions of supply chains including merger and acquisition, investment and/or controlling and inspecting on performance of financial supply chains. However, considering the capacity of banks in offering services, this range of services is capable to be developed greatly. For instance, by increasing collaborations between bank and supply chains, bank will be able to facilitate a ground for transaction cost reduction and effective management of liquidity 
through the chain by deriving and analyzing more expansively data related to the activities of supply chain partners. Offering settlement services and better management of prices fluctuation risk during supply chain are some of the other services which are mentioned in the agenda by financial services providers for such chains. To comprehend better method of presenting banking services to supply chains, we can demonstrate a general model of supply chain in Figure 2 as follows [2, 4].

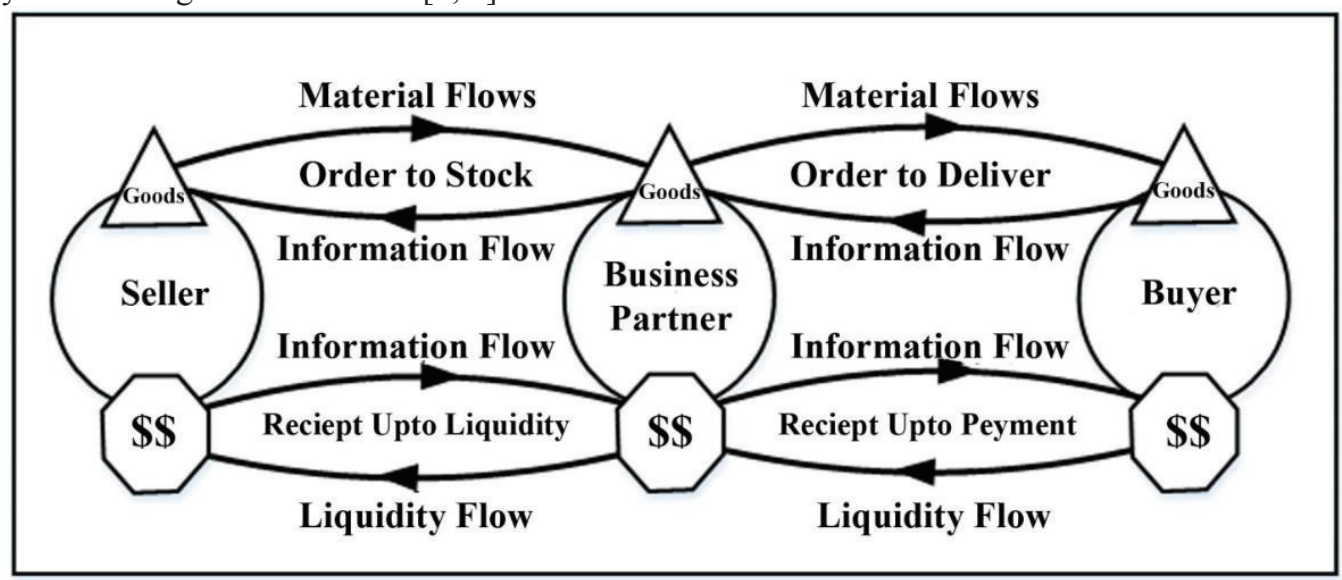

Figure 2 - General Supply Chain Architecture

In this structure, just one commercial partner is considered who has received goods from seller and handed over to buyer. The triangles in the figure and arrows connected to them show inventory flow, and also pentagons in the figure and arrows connected to them demonstrate cash flow in supply chain. Meanwhile, inventory flow from seller to buyer and in two processes of ordering goods from warehouse and instruction of sending goods and cash flow from buyer to seller, which they occur in two processes of developing payment statement and cashing statement. Thus, supply chains generally will benefit acceptable efficiency when each one of these 4 processes works well. In Figure 3, the role of financial services providers (FSP) is clarified in these processes. In this structure, FSP of supply chain is expected to offer regional and trans-regional financial services to the chain under any condition. Such services could be presented as follows which are recognized and analyzed from performance of various financial services providers [14].

Experience 1 - Distribution Network Management

Supply chain managers should constantly determine the best places for production and storage of goods considering the location of distribution and final consumers of their products, which this issue is recognized as management of distribution network. Now, this question may be raised that how the roles of FSPs could be exactly defined in this regard? FSPs usually obtain the decisions concerning their investment on projects based on Net Present Value (NPV) of the plan. Of course, it is obvious that value analysis of one company comparing with one network of companies will be much simpler. Hence, if it is revealed in FSP analysis that a great deal of financial saving will be occurred by making slight changes in distribution network of a chain, this saving amount could be regarded by bank on NPV of common projects with this chain. Thus, the main issue for FSPs through interaction with supply chains should be how to analyze the subjects related to supply network precisely and when to reconsider their interactions with these networks based on their predictions [18].

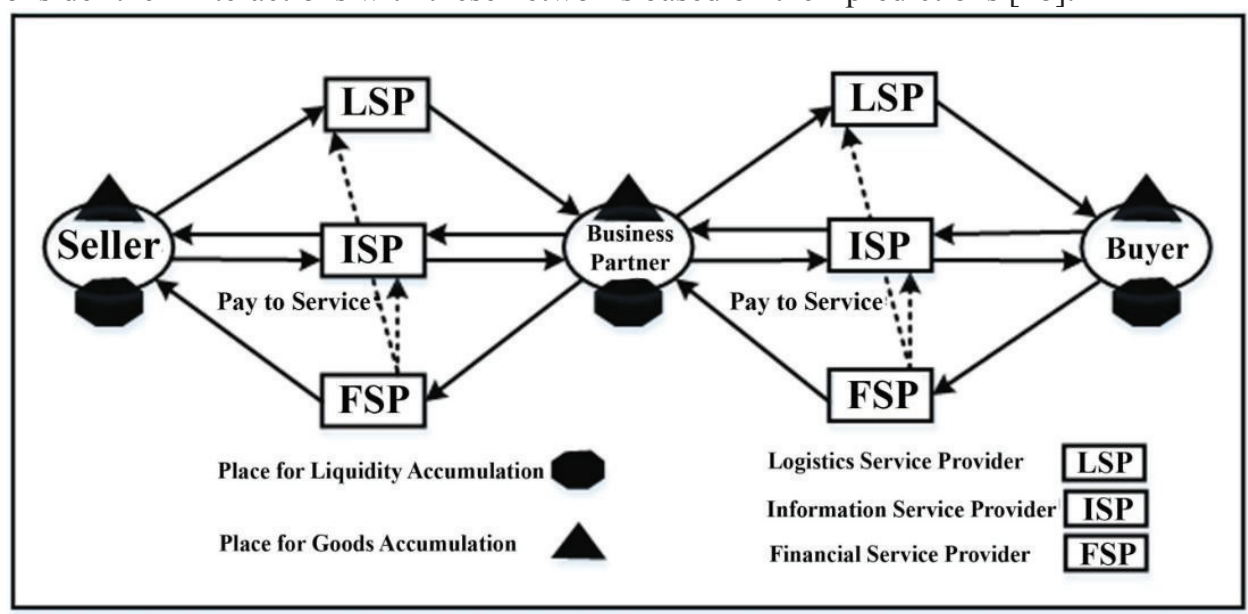

Figure 3 - FSPs' Place in Supply Chains 


\section{Experience 2 - Inventory Control}

The main question here is that how one financial foundation such as bank will be able to gain financial profits by managing its inventory in supply chains? Inventory usually is assessed based on inventory turnover, and inventory turnover is also the result of dividing the expenses of sold goods by the average of inventory. Companies usually intend to sell more and more goods while holding minimum inventory. On the other side, management should allocate a level of inventory in the company that avoids any probable shortage. Thus, company should set a balance between these two cases. Specialists of FSPs can provide consultation to managers of inventory management in some or all these cases. Some of these cases include: [9]

- Reviewing inventory intermittently in order to recognize depreciated products and to obtain decisions about amount of orders.

- Managing consumption rate of inventory and preserving safety stock at a desired level.

- Making use of ABC approach.

- Detecting a proper balance between storage expenses and ordering inventory.

Experience 3 - Distribution Strategies

Distribution strategies discuss distributing mechanisms for supply chains which have had the most advantages for these chains. These strategies include direct shipping, warehousing and/or cross-docking. In direct shipping, goods are handed over to selling points without requiring distributors. In warehousing, the goods are preserved in warehouse and they will be sent if required by customer. In the last method, goods are delivered directly from production to distribution without any warehousing. Taking each modality has some advantages and disadvantages and the expenses of transportation, maintenance and allocation are unique which are considered by FSP [9].

Experience 4 - Supply Chain Integration \& Strategic Unity

When bank enters supply chain in obtaining management decisions, it is considered a strategic partner of supply chain since then. Now, the services which a strategic partner could present will not be just financing. But cooperation and contribution in financial management of chain, information management, investment etc. are some of the other services which financial services providers could provide, and their quality and variation are increased in the current comparative structures [10].

Experience 5 - Developing Value-Added for Products

From product development viewpoint, FSP is not able to create value-added in tactical and/or strategic level for supply chain; however, FSP may be able at operational level to decrease time and facilitate cash cycle as follows by removing the existing obstacles on the way of financial transaction in the chain [17].

- Improving access to market: This approach will be meaningful when new marketing channels are developed for sale of products or services of one supply chain. In line with developing value-added in this process, banks should seek banking channels which their proposed financial services package have a supplementary role for a specific product or service.

- Operation improvement: Creating strong links among members of a chain may lead to higher productivity of chain and decrease in its expenses that no role is envisaged for developing value-added by banks.

- Technology improvement: Improvement in technologies used in supply, production, distribution, marketing and sale of goods is so effective in promoting efficiency and profitability of banks that this section is regarded out of bank operation scope.

Experience 6 - Making Financial Advantages

As mentioned in previous parts, making integration among material, information and cash flows in supply chains can have plenty of advantages including financial advantage for chains. Furthermore, it was discussed that for successful interaction with supply chains, banks should adjust their services with the existing processes in the chain. But method of applying this adjustment may raise a question. Hence, banks have paid attention to the following issues [6].

- Which information should be shared with bank and members of supply chain and how these information should be used?

- What integration level is required in supply chains?

- Which contribution cases should be considered by bank and members of chain?

Experience 7 - Product Design

Product design shall be in a way that not only meets various expectations and tastes, but also it shall provide no problem for supply chain in terms of production, transportation and distribution. On the strength of these issues, product design is an area which banks and other financial institutes are hardly able to make value added in it.

Experience 8 - Information Technology Systems \& Decision-Making Support

Information technology is an inseparable part of supply chain processes, and any relevant issues could be classified in three areas of data transfer and usage, making use of internet and e-commerce and infrastructure 
(internal and external). For the last two cases, the technologies such as financial EDI and RFID are usually used [18].

Experience 9 - Developing Value for Customers

Evaluation method of quality of goods and presented services by companies have been changed through time from quality assurance to customer satisfaction and finally to development of value for customer. This factor intends to extract the indicators upon which customer prefers a product or services of a company to that of others; hence he/she takes action to extract dimensions and indicators of developing value for customer and finally to apply technology in creating this value.

\section{Analyzing Experiences}

One of the approaches used previously by some strong organizations to decrease liquidity has been deferral in payments to suppliers. It seems obvious that using this approach enables the organization to handle its enterprise using less liquidity, and consequently create more profitability for shareholders.

The second point: Applying this approach and making this term longer have made suppliers to increase price of their products within a longer term which in turn it leads to depreciation of relation between sellers and buyers. Furthermore, this long time and variable of money payment to suppliers have encountered them with various problems in their payments which it causes instability in supply chain, and the entire chain will face high risk. Therefore, the aforesaid approach cannot be used as an effective approach for management of working capital in the existing organization in one chain; and the organizations should seek an appropriate approach for management of its working capital.

\section{Development \& Defining Conceptual Model of Financial Supply Chain Management and Supply Chain} Finance

To optimize working capital, cash-to-cash cycle is considered as one of the significant and fundamental factors. This cycle in fact demonstrates interval through which institutions pay cash amount to purchase goods and raw materials till they receive money or cash amount from buyer through selling their goods which is calculated as follows.

$$
\mathrm{C} 2 \mathrm{C}=\mathrm{DSO}+\mathrm{DIH}-\mathrm{DPO}
$$

$>$ Days Sales Outstanding (DSO): which demonstrates interval (days) between sale of product and receiving amount from buyer.

$>$ Days Payable Outstanding (DPO): which shows interval between purchasing goods and materials from supplier and paying its price to him.

$>$ Days Inventory Held (DIH): which demonstrates interval between receiving goods and raw materials in organization and selling manufactured goods or products to buyer.

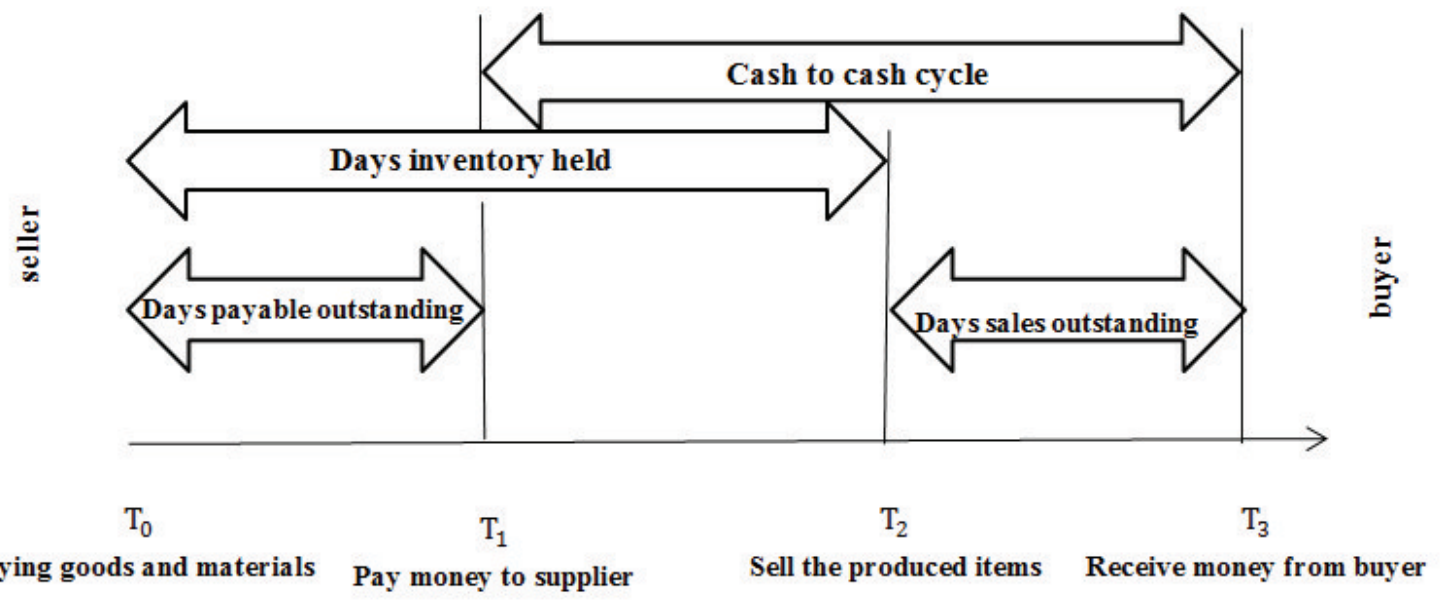

Figure 4 - Cash-To-Cash Cycle in a business

The investigations in the researches represent a negative relation between c2c cycle of institution and enterprise value (EV), in such a way that $25 \%$-reduction in cash-to-cash cycle increases enterprise value to about 7.5 percent. So working capital and cash-to-cash cycle are so important in the organizations and have been considered significantly.

As mentioned before, cash-to-cash cycle has a great importance in management of working capital. This cycle can be classified through another standpoint to the following three sub-cycles:

1) Purchase to payment cycle: It focuses on supply and management of expenses in supply part of the organization. 
2) Prediction to completion cycle: It emphasizes on manufacturing, warehousing, predicting and processing orders.

3) Order to cash cycle: It discusses sale and income management in the part of buyer in the chain.

There are the following problems in purchase to payment cycle: interaction with suppliers, payment of cash amounts and the issues and problems related to DPO. The issues and problems in prediction to completion cycle include the expenses related to liquidity maintenance, materials and goods which may lead to less rate of capital return. Eventually, issues and problems which may be encountered through order to cash return cycle are increasing DSO term due to various reasons such as noncompliance of invoice with purchase order.

Previously, to prevent the said problems and to improve working capital of the organization, various approaches were used that most of them were focused on one organization, and it was tried to optimize the desired working capital. Some of the major approaches are as follows:

A- Compulsory Extension (DPO)

Major and chief purchasers made their best to apply their power to postpone their financial payments to less strong and smaller suppliers. Using such approach leads to delayed payments to the higher suppliers in the chain and on the contrary to the working capital transfer to the higher parts of the chain, it resulted in weakening the commercial relation of the organization with suppliers in long term.

B-Applying Inventory Reduction Approaches, including on-time production

In this approach, it was tried to decrease inventory of the organization using some policies. However, in this condition organization may encounter shortage due to inaccuracy of predictions and; and bring about lack of inventory for the organization.

C-Compulsory Reduction (DSO)

This approach is used by powerful suppliers. In such status, suppliers made purchasers to pay their relevant payments sooner by making use of their power and influence. This method also cause reduction in commercial relations within a long term on the contrary to the cash transfer to the lower part of chain and facilitation of a series of problems for lower levels in the chain.

As it was seen, the above approaches, which seek deferment the payments relayed to purchaser and/or acceleration in the time for receiving the cash by seller, intend to optimize working capital for the entire chain. To reach a condition in which working capital is optimized in the entire chain, it requires coordination and integration of all members of the chain. Otherwise, by transferring expenses load from one member to another member of the chain, major and various risks will be occurred for the chain, including:

- Risk of losing client

- Risk of failure to continue business

- Risk of suppliers' persistence

- Inflammation in expenses of materials

The above-mentioned points have made the organization to amend their strategies in the area of working capital. Nowadays that organizations are growing and working increasingly to prevent occurrence of such problems and to preserve competitive conditions, they should find new approaches to manage financial flow in their own chain. Besides the aforesaid problems, some of the other problems which threaten supply chain are as follows:

- Raw materials and final products in supply chain are financed several times and by different banks.

- Cash flow is usually ineffective. Cash flows are not corresponding at top and bottom of chain which it leads to failure in cash balance.

- Goods can be financed based on the validity of the strongest member of supply chain, however, it occurs rarely.

Considering the above-mentioned issues, some of the rules and requirements of implementing financial supply chain management could be summarized as follows:

* Financial integration in supply chains requires simultaneous coordination in information and cash flow. To gain such goal, three major parts of Logistic Service Provider (LSP), Financial Service Provider (FSP) and Information Service Provider (ISP) should have interaction in an integrated and coordinated manner.

* Responsibility of managing materials flow, facilitating cash flow and providing required information tools in supply chains will be the responsibility of LSP, FSP and ISP, respectively.

* Presented services by FSPs should be accompanied by applying technological infrastructures of information flow management and Financial Electronic Data Exchange Services (Financial EDI) in supply chain. It should be mentioned that since this group of services has no added value essentially from financial foundation, supply chains usually seek its presenting FSP with the lowest price. Thus, competition is also so high in offering financial EDI services.

* As it was mentioned before, optimized usage of properties of supply chain can demonstrate efficiency in supply chain. Among the KPIs applied in the chain is amount of Return on Assets (ROA) which can 
be deemed as a coefficient from amount of assets and profitability of company. Therefore, smaller companies with less capital amount should increase its sale to enhance ROA, vice versa. From this viewpoint, LSPs, FSPs and ISPs can increase ROA of supply chain by reducing receivable accounts.

* Cash Management Services (CMS) usually offer by the banks for the clients which have various working registries. Bank usually controls these businesses intermittently and/or automatically takes action to replace and/or manage liquidity in the same. Thus, CMS can be applied similarly for the members of a supply chain. Hence, by receiving information from LSP and ISP, FSP can upgrade financial balance of chain members constantly.

* By managing cash flow, FSP controls and predicts working capital of supply chain members to be able to calculate amount of payments with a specified range of risk and credit.

* Using data gathered from ISP and LSP particularly for depreciable goods, FSP will be able to estimate their real value in the form of collateral value in supply chain. This collateral value seems to be so important by the time of presenting credit by FSP to a partner in supply chain upon estimating his payable account.

* FSPs offer a vast range of electronic financial services such as paying bills, salary, wage and other statements in electronic manner to the organizations, but these services are considered as a requirement for companies and have no added value for supply chain. Thus, by recognizing types of performed activities in supply chain in which they are serving services, banks should be able to offer new creative approaches to their members, particularly in electronic commerce, which other rivals are deprived of it.

* Besides finance services which are specific to supply chains by considering general credit of chain in granting financial facilities and supply, banks can assist financial supply of company in the chain upon recognizing weak companies in its financial systems and properties to improve efficiency in all supply chain.

* ISPs, FSPs and LSPs which are usually engaged in as suppliers of third party services to supply chains should focus on the activities of active companies in the area of supply chain to take an appropriate action in proportionate with the requirement of its clients and the nature of their enterprise.

\section{Conclusion}

Nowadays, considering technological evolutions and establishment of intense competition to achieve a greater share in market, companies and organizations are made to attend and participate in the area of network economies, and in this regard, in the area of their supply chain, they intend to have an effective management on goods and information flows and financial flow of their enterprise. Although attitude toward this approach has some advantages and efficiencies for institutions, it brings a plenty of problems and complexities for management of financial crises, liquidity and working capital of institutions and their commercial partners. To dominate such problems besides development of concepts of supply chain management and logistic, financial supply chain management (FSCM) was developed too in order to minimize inefficiencies of financial flows in supply chain using financial, engineering and managerial approaches, and to facilitate an effective area of cash amounts and working capital all throughout supply chain by making use of various tools and techniques of chain finance and/or SCF. Therefore, it can be said in general that supply chain of goods includes planning, supply, production and distribution processes; and chain finance presents the activities related to planning, coordination and controlling financial resources in supply chain by assistance of the institutes presenting financial services. In fact, SCF coordinates operational flow with financial flow within supply chain.

This subject demonstrates that today organizations require new and proper tools and techniques for financial exchange and working capital management of their institution and chain since the supply chains have become larger and their conditions are more complicated. They seek new solutions which enhance responsiveness and responsibility, clarity, efficiency, expense optimization, liquidity and predictability in their supply chains. Hence, to change approach and role of financial service providers from just suppliers of financial resources to the commercial partners of economic institutions, a great amount of managerial duties of financial flows of chain businesses are defined in exchange of FSPs, and they are executed in a more desired manner regarding capabilities and capacities of banks and financial institutes. To gain this purpose, banks also intend to develop new approaches, solutions and means to be able to offer more services in financial supply, performing commercial exchange and management of working capital to their clients in the form of business networks and supply chains in the form of chain finance methods or SCF. Thus it can be inferred that financial supply chain management is considered as an approach to improve efficiency and financial performance of supply chains, and the main objective of applying SCF is to save expenses with integrating relations among partners of supply chain and using the last tools of finance for them.

It was mentioned in this article that LSPs are responsible to keep inventories optimized in supply chains, FSPs have similar roles in these chains concerning level of liquidity. Similarly, receivable and payable accounts could be considered as "cash reserves" that FSP tries to manage them properly and develop an optimized cash 
flow cycle in supply chain. This issue is used in presenting current financial services in supply chains as financial electronic data exchange services (Financial EDI), Cash Management Services (CMS) and punctual payment of mobile receivable accounts. Hence, by developing coordination and integration in supply chain, LSPs, FSPs and ISPs can manage financial risks in supply chain which leads to enhancement of value flow.

\section{References}

[1] Kristofik, Peter, et al., 2012. Financial Supply Chain Management Challenges and Obstacles, ACRN Journal of Entrepreneurship Perspectives, Vol. 1, pp. 132-143. ISSN 2224-9729.

[2] Honig, Hans, 2013. Financial Supply Chain Management. Deloitte.

[3] Hausman, Warren H. 2005. Financial Flows \& Supply Chain Efficiency, Stanford University, Department of Management Science \& Engineering.

[4] Hatfield, Thea, et al. 2007. Guide to Financial Supply Chain Management. HSBC Bank, Commercial Banking. London: Euro money publications.

[5] Cronie, G. 2011. Guide to Financial Supply Chain Optimization. Wholesale Banking.

[6] Stephenson, M., Hutter, L. 2009. Supply Chain Finance: Releasing working capital within the supply chain. Deloitte.

[7] Baerentsen, Dan Xu and Thorstenson, Anders. 2012. The Impact of Supply Chain Finance on Corporate Performance: Improving Supply Chain Efficiency and Increasing Profitability. Aarhus University, Business and Social Science. Master Thesis in MSc. Finance.

[8] Fujimori, Yoshiro and Bitran, Gabriel R. 2005. Financial Services in Supply Chain (Success Factors and Future Opportunities for Traditional Financial Institutions, MIT Sloan School of Management. Thesis for MSc Degree of Science in Management.

[9] GT Nexus. 2010, 15 Best Practices for Your Financial Supply Chain.

[10] SAP, 2010. Financial Supply Chain, SAP Financial Supply Chain \& Dispute Management.

[11] Presutti W, Mawhinney J, 2007, the supply chain-finance link”, Supply Chain Mng. Rev.

[12] Camerinelli E. 2012, Supply Chain Finance Software Vendors: Trade Card", Aite Group

[13] Fairchild A., 2005, intelligent matching: integrating efficiencies in the financial supply chain", Supply Chain Management International Journal

[14] Ross SA, Westfield RW, Jaffe J, 2005, Corporate finance, 7th edn, McGraw-Hill, Boston

[15] Hofmann E, 2005, Supply chain finance solution: Relevance, Proposition, Market Value

[16] Braun A, 2008, Corporate cash management trends - part 3: the financial supply chain

[17] Sadlovska V, 2007, Technology platforms for supply chain finance”, Aberdeen Study, Boston

[18] Gordy M, 2000, A comparative anatomy of credit risk models", J Bank Finance

[19] B. Johnson, 2001, the logic of theory development and testing, university of Utah 